\title{
Association of Ki-67 Labelling Index and IL-17A with Pituitary Adenoma
}

\section{Brigita Glebauskiene $\left(\mathbb{D},{ }^{1}\right.$ Rasa Liutkeviciene, ${ }^{1,2}$ Alvita Vilkeviciute $\left(\mathrm{D},{ }^{2}\right.$ Inga Gudinaviciene, ${ }^{3}$ Aurelija Rocyte, ${ }^{4}$ Dovile Simonaviciute, ${ }^{5}$ Ruta Mazetyte ${ }^{D},{ }^{5}$ Loresa Kriauciuniene $\mathbb{D}^{1,2}$ and Dalia Zaliuniene $\mathbb{D}^{1}$}

${ }^{1}$ Lithuanian University of Health Sciences, Medical Academy, Department of Ophthalmology, Lithuania

${ }^{2}$ Neuroscience Institute, Lithuanian University of Health Sciences, Medical Academy, Lithuania

${ }^{3}$ Lithuanian University of Health Sciences, Medical Academy, Department of Pathology, Lithuania

${ }^{4}$ Lithuanian University of Health Sciences, Medical Academy, Department of Laboratory Medicine, Lithuania

${ }^{5}$ Lithuanian University of Health Sciences, Medical Academy, Lithuania

Correspondence should be addressed to Brigita Glebauskiene; bglebauskiene@gmail.com

Received 5 February 2018; Revised 17 April 2018; Accepted 3 May 2018; Published 31 May 2018

Academic Editor: Stefan Linsler

Copyright (c) 2018 Brigita Glebauskiene et al. This is an open access article distributed under the Creative Commons Attribution License, which permits unrestricted use, distribution, and reproduction in any medium, provided the original work is properly cited.

\begin{abstract}
The aim of the present study was to determine if the Ki-67 labelling index reflects invasiveness of pituitary adenoma and to evaluate IL-17A concentration in blood serum of pituitary adenoma patients. The study was conducted in the Hospital of Lithuanian University of Health Sciences. All pituitary adenomas were analysed based on magnetic resonance imaging findings. The suprasellar extension and sphenoid sinus invasion by pituitary adenoma were classified according to Hardy classification modified by Wilson. Knosp classification system was used to quantify the invasion of the cavernous sinus. The Ki-67 labelling index was obtained by immunohistochemical analysis with the monoclonal antibody, and serum levels of IL-17A were determined by enzyme-linked immunosorbent assay (ELISA). Sixty-nine PA tissue samples were investigated. Serum levels of IL-17A were determined in 60 patients with PA and 64 control subjects. Analysis revealed statistically significantly higher Ki-67 labelling index in invasive compared to noninvasive pituitary adenomas. Median serum IL-17A level was higher in the pituitary adenoma patients than in the control group. Conclusion. IL-17A might be a significant marker for patients with pituitary adenoma and Ki-67 labelling index in case of invasive pituitary adenomas.
\end{abstract}

\section{Introduction}

Pituitary adenoma (PA) is an intracranial tumour arising from the hormone-secreting epithelial cells in the anterior lobe of hypophysis with reported estimated prevalence rates ranging between $14.4 \%$ and $22.5 \%$ in pooled autopsy and radiological series, respectively [1]. PA is covered by dura and is located in the hypophyseal fossa of the sphenoid bone and surrounded by the two cavernous sinuses laterally [2]. Although PA is considered as a benign tumour, it frequently invades the sphenoid bone and the cavernous sinus [3-10], and if the direction of expansion is suprasellar, it compresses the optic chiasm [11-19]. About 35\% of all pituitary neoplasms are considered as invasive tumours (Figure 1) [9]. PA can transform to a malignant tumour as well [20]. However, PAs can easily expand laterally without invasion, because the medial wall of the cavernous sinus is a thin dural bag $[21,22]$. It is important to differentiate the invasive PA growth from lateral growth without invasion because it can influence treatment and prognosis of PA [23].

In order to prognosticate the course of PA, attention has been drawn to the scientific surveys about the invasiveness markers, such as Ki-67 labelling index (LI), IL-17A, and several others [24-26]. The Ki-67 is supposed to be one of the invasiveness markers of PA [5, 10, 24, 26-32]; despite this fact, some studies have shown controversial data [3335]. It has been found that IL-17A plays an important role in the development of various tumours, for example, breast 


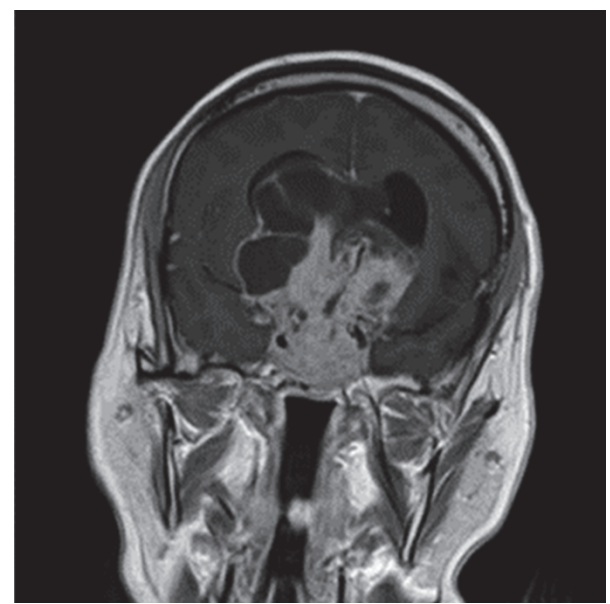

FIGURE 1: Invasive pituitary adenoma.

cancer, hepatocellular carcinoma, and cervical cancer [3639]. However, some studies have revealed that IL-17A inhibits the development of tumours $[40,41]$ and there is only one survey that analyses the IL-17A impact on the PA growth $[42,43]$. We also hypothesized that the development of PA can be influenced by the concentration of IL-17 A.

Therefore, the aim of the present study was to determine possible molecular markers which may serve as diagnostic and prognostic PA markers.

\section{Materials and Methods}

Permission to undertake the present study (number P29/2003) was obtained from the Biomedical Research Ethics Committee of Lithuanian University of Health Sciences (Kaunas, Lithuania). The study was conducted in the Departments of Ophthalmology, Neurosurgery, and Laboratory Medicine, Lithuanian University of Health Sciences Hospital (Kaunas, Lithuania).

Sixty-nine PA tissue samples were investigated. Serum levels of IL-17A were determined in 60 patients with PA and 64 control subjects. Specimens of PA and blood serum were taken before treatment.

The inclusion criteria were as follows: (1) determined and confirmed PA via MRI; (2) patient's general good condition; (3) patient's consent to take part in the study; (4) age $\geq 18$ years; (5) no other brain tumours or tumours with other localizations, intracranial infection, demyelinating lesions, or cerebrovascular disease.

The control group for IL-17A evaluation was made of 64 healthy subjects, who were admitted to the Hospital of Lithuanian University of Health Sciences Department of Ophthalmology for preventive ophthalmological evaluation, considering the patient's age and gender in the PA group. Therefore, the medians of patient age in the control group and in the PA group did not differ statistically significantly $(\mathrm{p}<0.05)$. Demographic and clinical data are shown in Table 1.

Brain Imaging. All pituitary adenomas were analysed based on magnetic resonance imaging (MRI) findings. The preoperative MRI investigations were performed with 1,5 $\mathrm{T}$ MRI scanners (Siemens MAGNETOM Avanto, 1,5 T

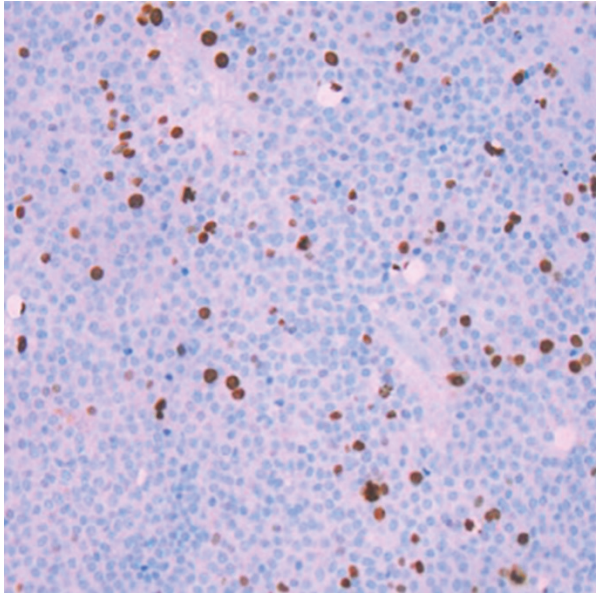

FIGURE 2: Immunostaining for Ki-67 in pituitary adenoma. Only the dark brown stained nuclei were considered as immunopositive.

Philips ACHIEVA) using a head coil and a standard pituitary scanning protocol, obtaining T1W sagittal and coronal and T2W/TSE coronal precontrast images, and T1W coronal and sagittal Gadolinium-enhanced MR images with the intravenous agent gadodiamide (Omniscan, GE Healthcare). The retrospective analysis of MRI data was conducted by an experienced radiologist. The suprasellar extension and sphenoid sinus invasion by PA were classified according to the Hardy classification, modified by Wilson (Table 2) [23]. The degree of suprasellar and parasellar extensions was graded as stages A-E. The degree of sellar floor erosion was graded as grades I-IV. Grade III shows localized sellar perforation, and grade IV shows diffuse destruction of sellar floor, which are the signs of invasive PA. The Knosp classification system (Table 3) [5] was used to quantify the invasion of the cavernous sinus. Grade 3 and 4 pituitary tumours were considered to be invasive.

Ki-67 labelling index. The Ki-67 LI was obtained by performing an immunohistochemical analysis with the monoclonal antibody (clone SP6; Spring Bioscience Corporation). The Ki-67 LI was defined as the percentage of positive staining tumour cells.

Ki-67 LI evaluation was carried out in the Clinic of Pathological Anatomy of the LUHS by the qualified pathologist. The biological markers of proteins were analysed according to the immunohistochemical analysis protocol in paraffin sections by the Ventana BenchMark XT staining procedure (Ventana Medical Systems, Tucson, Arizona, USA). Paraffin sections were dewaxed using Ventana reagent. Ventana Cell Conditioning Solution $(\mathrm{pH} 8.4)-100^{\circ} \mathrm{C} 60 \mathrm{~min}$. was used in order to restore antigenic epitopes. Those sections were incubated with monoclonal antibodies for $32 \mathrm{~min}$. at $37^{\circ} \mathrm{C}$ and identified with Ventana iVIEW DAB Detection Kit. At the end of IHC reaction, sections were contrasted with Gill's Hematoxylin Solution, coloured with bluing reagent of an aqueous solution of buffered lithium carbonate, and covered with glass slides (Figure 2).

IL-17A. The serum IL-17A level was measured by enzymelinked immunosorbent assay (ELISA) according to the 
TABLE 1: Demographic and clinical data.

\begin{tabular}{|c|c|c|c|}
\hline Characteristic & $\begin{array}{c}\text { PA group } \\
n=60\end{array}$ & $\begin{array}{c}\text { Control group } \\
\mathrm{n}=64\end{array}$ & p value \\
\hline \multicolumn{4}{|l|}{ Gender } \\
\hline Males, n (\%) & $22(36.7)$ & $14(21.9)$ & \multirow{2}{*}{0.070} \\
\hline Females, n (\%) & $38(63.3)$ & $50(78.1)$ & \\
\hline Age at onset (years) $(\mathrm{min} / \mathrm{max} /$ median$)$ & $24 / 83 / 50$ & $19 / 82 / 55$ & 0.465 \\
\hline
\end{tabular}

Symptoms:

(1) Visual disturbances (decreased visual acuity, visual field defects,

etc.)

(2) Headache

39

(3) Weakness

25

(4) Acromegaly (exaggerated growth of the hands and feet, with thick

fingers and toes, enlargement of the lower lip and nose, etc.)

(5) Prolactinoma symptoms (disruption of menstrual cycle, milk

production unrelated to pregnancy or nursing, etc.)

\begin{tabular}{lrr}
\hline Recurrence: & & NA \\
Absent/present & $51 / 9$ & NA \\
\hline Invasiveness: & & - \\
Invasive/noninvasive & $25 / 35$ & NA \\
\hline Surgery/conservative treatment & $55 / 5$ & - \\
\hline
\end{tabular}

TABLE 2: Hardy classification, modified by Wilson [21].

\begin{tabular}{|c|c|c|c|c|c|c|}
\hline \multirow{3}{*}{ Grades } & \multirow{3}{*}{$\begin{array}{l}\text { Sellar floor } \\
\text { erosion }\end{array}$} & \multicolumn{5}{|c|}{ Extrasellar extensions } \\
\hline & & \multicolumn{2}{|c|}{ Suprasellar extension } & \multicolumn{3}{|c|}{ Parasellar extension } \\
\hline & & A & $\mathrm{B}$ & $\mathrm{C}$ & $\mathrm{D}$ & $\mathrm{E}$ \\
\hline Grade I & $\begin{array}{l}\text { Sella normal or } \\
\quad \text { focally } \\
\text { expanded; } \\
\text { tumor }<10 \mathrm{~mm}\end{array}$ & $\begin{array}{l}\text { PA expanding } \\
\text { into the } \\
\text { suprasellar } \\
\text { cistern }\end{array}$ & $\begin{array}{l}\text { Anterior } \\
\text { recesses of the } \\
\text { third ventricle } \\
\text { obliterated }\end{array}$ & $\begin{array}{l}\text { The floor of the } \\
\text { third ventricle } \\
\text { grossly } \\
\text { displaced }\end{array}$ & $\begin{array}{l}\text { An intracranial extension } \\
\text { into the anterior, middle, } \\
\text { or posterior fossa } \\
\text { (intradural) }\end{array}$ & $\begin{array}{c}\text { An intracranial } \\
\text { extension into or } \\
\text { beneath the cavernous } \\
\text { sinus (extradural) }\end{array}$ \\
\hline Grade II & $\begin{array}{l}\text { Sella enlarged; } \\
\text { tumor } \geq 10 \mathrm{~mm}\end{array}$ & & & & & \\
\hline Grade III & $\begin{array}{c}\text { Localized sellar } \\
\text { perforation }\end{array}$ & & & & & \\
\hline Grade IV & $\begin{array}{c}\text { Diffuse } \\
\text { destruction of } \\
\text { the sellar floor }\end{array}$ & & & & & \\
\hline
\end{tabular}

manufacturer's instructions (ThermoFisher Scientific Human IL17A ELISA Kit).

Solutions for the analysis were prepared according to the recommendations of the manufacturer. Appropriate solutions of $2000 \mathrm{pg} / \mathrm{mL}, 1000 \mathrm{pg} / \mathrm{mL}, 500 \mathrm{pg} / \mathrm{mL}, 250 \mathrm{pg} / \mathrm{mL}, 125$ $\mathrm{pg} / \mathrm{mL}, 62.5 \mathrm{pg} / \mathrm{mL}, 31.25 \mathrm{pg} / \mathrm{mL}$, and $0 \mathrm{pg} / \mathrm{mL}$ of IL-17A were prepared in order to obtain a calibrated protein standard. 50 $\mu \mathrm{L}$ biotinylated antibody was added to each ELISA 96-well plate. $50 \mu \mathrm{L}$ of standard or $50 \mu \mathrm{L}$ of sample was pipetted into the wells twice. The wells were covered and incubated at the room temperature for 2 hours and then washed 3 times with washing buffer solution. $100 \mu \mathrm{L}$ of streptavidin protein that is conjugated to horseradish peroxidase was added to each well and then plates were covered and incubated for 1 hour. After that, the wells were washed 3 times again with washing buffer solution. Substrate solution was added to each well and they were incubated for $30 \mathrm{~min}$. at the room temperature. The reaction was performed in the dark. Then $100 \mu \mathrm{L}$ of Stop solution was added to each well and as a result blue colour changed into yellow. Absorption was evaluated by microplate reader at $450 \mathrm{~nm}$ and $550 \mathrm{~nm}$ wavelengths. The difference between optical densities at these wavelengths was used to assess the concentration. Samples concentration was evaluated by using the standard curve.

Statistical analysis. Statistical analysis was performed using the SPSS / W 23.0 software (Statistical Package for the Social Sciences for Windows, Inc., Chicago, Illinois, USA). Normality of the distribution was tested with ShapiroWilk and Kolmogorov-Smirnov statistics. Mann-Whitney U test was conducted to compare nonparametric values. The 
TABLE 3: Knosp classification of pituitary adenoma [5].

\begin{tabular}{|c|c|}
\hline Grade 0 & $\begin{array}{l}\text { No involvement of the cavernous sinus } \\
\text { (normal condition) }\end{array}$ \\
\hline Grade 1 & $\begin{array}{l}\text { The tumor pushes into the medial wall of the } \\
\text { cavernous sinus, but does not go beyond a } \\
\text { hypothetical line extending between the } \\
\text { centers of the two segments of the internal } \\
\text { carotid artery (noninvasive PA) }\end{array}$ \\
\hline Grade 2 & $\begin{array}{c}\text { The tumor goes beyond hypothetical line, } \\
\text { but without passing a line tangent to the } \\
\text { lateral margins of the artery itself } \\
\text { (noninvasive PA) }\end{array}$ \\
\hline Grade 3 & $\begin{array}{l}\text { The tumor extends laterally to the internal } \\
\text { carotid artery within the cavernous sinus } \\
\text { (invasive PA) }\end{array}$ \\
\hline Grade 4 & $\begin{array}{l}\text { Total encasement of the intracavernous } \\
\text { carotid artery (invasive PA) }\end{array}$ \\
\hline
\end{tabular}

data are presented as absolute numbers with percentages in brackets and as median with min and max values. Differences were considered statistically significant when $\mathrm{p}<0.05$.

\section{Results}

Ki-67 labelling index. 69 PA tissue samples were investigated. $\mathrm{Ki}-67 \mathrm{LI}$ was evaluated in 37 women (53.6\%) and 32 men $(46.4 \%)$. The results showed that there was no significant difference in the Ki-67 LI between women and men ( $\mathrm{p}=$ 0.092).

Immunohistochemistry for $\mathrm{Ki}-67$ revealed a $\mathrm{LI}<1 \%$ in $49.3 \%$ of patients with PA, Ki-67 LI $1 \%$ in $24.6 \%$, and $\mathrm{Ki}-$ $67 \mathrm{LI}>1 \%$ in $26.1 \%$ of patients. Further analysis showed statistical significance in relation to tumour invasiveness ( $\mathrm{p}$ $=0.039$ ) (Table 4). However, Ki-67 LI analysis did not reveal any correlation with PA recurrence $(\mathrm{p}=0.6)$ and tumour growth direction $(p>0.05)$ (Table 5). There were no statistical differences in the Ki-67 LI in relation to the Hardy, modified by Wilson, as well as Knosp classifications ( $\mathrm{p}>0.05$ ) (Table 6).

The concentration of IL-17A in blood serum. Serum levels of IL-17A were determined in 60 patients with PA and 64 control subjects. IL-17A analysis showed a significant difference between the median serum IL-17A level in the PA patients group (median 42.12; $\min 1.95$; $\max 76.80$ ) and the control group (median 8.19; min 0.39; max 74.57). However, analysis did not show any statistical significance comparing different growth types of PA ( $p>0.05)$ (Table 7).

\section{Discussion}

$\mathrm{Ki}-67 \mathrm{LI}$ is referred to as an indicator of aggressive behaviour in the classification of endocrine tumours [44]. Numerous studies have analysed the impact of Ki-67 LI on PA invasiveness and recurrence $[5,24,26-35,45]$ but only few studies have investigated the associations between the expression of Ki-67 and PA growth direction [27], and data still remain controversial.

In the present study we found that invasive PAs have significantly higher Ki-67 LI compared to noninvasive PAs.
Several studies confirmed our results. Thirty-eight invasive and 65 noninvasive PA tumours were analysed in the study conducted by Mastronardi et al. [27]. The research has revealed that Ki-67 LI could be useful marker in the determination of invasive PAs, even if this Ki-67 LI had no significant correlation with tumour size [27]. Wierzbicka-Tutka et al. also have found statistically significant correlation between Ki-67 LI and tumour size and invasiveness [26]. Zaidi et al. have confirmed that Ki-67 LI also could be used as an independent predictor marker for aggressive PAs growth in atypical PAs cases [31]. Knosp et al. [5] have found a significantly higher rate of Ki-67 LI in PAs with surgically observed invasion into the cavernous sinus space compared to noninvasive PAs ( $\mathrm{p}<0.001)$. Thapar et al. [28] have analysed Ki-67 LI in 33 invasive and in 37 noninvasive PAs and revealed that invasive PAs had a higher Ki-67 LI than noninvasive PAs. They have established a threshold LI of $3 \%$ to distinguish invasive from noninvasive PAs. Kitz et al. [29] have proven that PAs with histologically proven dural infiltration (real invasiveness) had a significantly higher Ki-67 LI compared to noninvasive PAs ( $\mathrm{p}<0.001)$. Another study done by Sadeghipour et al. [30] has analysed Ki-67 LI in 176 patients with PAs, who were treated surgically. Thirty-six patients had recurrent episodes and 11 of 176 patients had an invasive tumour. Scientists revealed that the group of invasive PAs had a higher Ki-67 LI compared to the noninvasive group. However, the difference in Ki67LI between recurrent and nonrecurring PAs groups was not statistically significant [30].

However, some authors have found no association between the rate of Ki-67 LI and PA invasiveness [33-35]. Yarman et al. [33] concluded that Ki-67 LI expression had no correlation with invasive PAs. Dubois et al. [34] also concluded that Ki-67 LI had no independent prognostic value of PA invasiveness. Gandour-Edwards et al. [35] examined 10 invasive PAs involving the sphenoid sinus and 10 noninvasive PAs. They have not found statistical significant difference between them as well.

Although we have not found any significant correlation between Ki-67 LI and PA recurrence, Paek [45] et al. have demonstrated that PAs with recurrence had a significantly higher Ki-67 LI than adenomas without recurrence $(0.56 \%)$ ( $p=0.027)$. Landeiro et al. have evaluated 35 patients with giant nonfunctioning PAs. In their survey, 30 patients had $\mathrm{Ki}-67 \mathrm{LI}<3 \%$ and, in those patients, recurrence was found in $6.67 \%$. Five patients had $\mathrm{Ki}-67 \mathrm{LI}>3 \%$, and 3 of them were diagnosed with recurrence (60\%) [32].

Also we found no correlation between Ki-67 LI and tumour growth direction. Kyung-Il Paek et al. have found that the Hardy classification D (1.08\%) had a higher Ki67 labelling index than the others, but without a statistical significance $(p=0.460)$ [45]. We also found that there were no statistical differences in the Ki-67 LI in relation to the Hardy, modified by Wilson, as well as Knosp classifications.

To our knowledge, only one study has explored IL-17A concentration in the serum of patients with PA, but no studies have investigated the association between serum IL-17 and PA growth type. Qiu et al. [42, 43] have investigated IL$17 \mathrm{~A}$ serum concentration level of $76 \mathrm{PA}$ patients, and they have observed that serum level of IL-17A was significantly 
TABLE 4: Ki-67 labeling index considering invasiveness of pituitary adenoma.

\begin{tabular}{lccc}
\hline PA & $<1 \%$ & Ki-67 LI & p \\
\hline $\begin{array}{l}\text { Noninvasive PA } \\
\mathrm{n}=26(37.7 \%)\end{array}$ & $16(47.1 \%)$ & $2(11.8 \%)$ & $8(44.4 \%)$ \\
$\begin{array}{l}\text { Invasive PA } \\
\mathrm{n}=43(62.3 \%)\end{array}$ & $18(52.9 \%)$ & $15(88.2 \%)$ & $10(55.6 \%)$ \\
\hline
\end{tabular}

*: $\chi^{2}$ test; LI: labelling index; PA: pituitary adenoma.

TABLE 5: Ki-67 labelling index in pituitary adenoma tissue considering growth direction of pituitary adenoma.

\begin{tabular}{|c|c|c|c|c|}
\hline \multicolumn{2}{|c|}{ PA growth direction } & $\begin{array}{c}\text { Ki-67 LI }<1 \% \\
(\mathbf{n})\end{array}$ & $\begin{array}{c}\text { Ki-67 } \mathbf{L I} \geq \mathbf{1} \% \\
\text { (n) }\end{array}$ & p value $*$ \\
\hline \multirow{2}{*}{ Suprasellar growth } & Yes & 24 & 26 & \multirow{2}{*}{$\mathrm{p}=0.731$} \\
\hline & No & 10 & 9 & \\
\hline \multirow{2}{*}{ Paracavernous growth } & Yes & 10 & 15 & \multirow{2}{*}{$\mathrm{p}=0.245$} \\
\hline & No & 24 & 20 & \\
\hline \multirow{2}{*}{ Sphenoidal growth } & Yes & 16 & 21 & \multirow{2}{*}{$\mathrm{p}=0.281$} \\
\hline & No & 18 & 14 & \\
\hline
\end{tabular}

*: Student's t-test; LI: labelling index; PA: pituitary adenoma.

TABLE 6: The Ki-67 LI in relation to the Hardy, modified by Wilson, and Knosp classifications.

\begin{tabular}{ll}
\hline Classification & Ki-67 LI, median (IQR) \\
\hline Hardy-suprasellar & $2.5(1.00)$ \\
0 & $2.0(1.25)$ \\
A & $3.0(2.00)$ \\
B & $2.0(2.00)$ \\
C & \\
\hline Hardy-parasellar $*$ & 0.564 \\
0 & $2.0(2.00)$ \\
E & $3.0(2.00)$ \\
E,D & $2.5(1.00)$ \\
\hline Knosp & \\
0 & $2.0(2.00)$ \\
1 & $3.0(2.00)$ \\
2 & $2.0(2.00)$ \\
3 & $3.0(1.00)$ \\
4 & $3.0(2.00)$ \\
\hline
\end{tabular}

*: Kruskal-Wallis test; LI: labelling index.

TABLE 7: Serum levels of IL-17A in patients with pituitary adenoma and in controls considering growth type of pituitary adenoma.

\begin{tabular}{|c|c|c|c|}
\hline PA growth type & Group (n) & $\begin{array}{l}\text { IL-17A concentration } \\
(\mathrm{pg} / \mathrm{mL}) \\
\mathrm{min} / \mathrm{median} / \mathrm{max}\end{array}$ & p value $*$ \\
\hline \multirow{2}{*}{ Invasiveness } & Invasive (29) & $1.95 / 42.12 / 76.80$ & \multirow{2}{*}{$\mathrm{p}=0.701$} \\
\hline & Noninvasive (25) & $3.10 / 42.12 / 76.80$ & \\
\hline \multirow{2}{*}{ Recurrence } & Recurrent PA (5) & $1.95 / 42.12 / 76.80$ & \multirow{2}{*}{$\mathrm{p}=0.664$} \\
\hline & Nonrecurrent PA (49) & $3.10 / 42.12 / 76.80$ & \\
\hline \multirow{2}{*}{ Suprasellar growth } & Yes (38) & $1.95 / 42.12 / 76.80$ & \multirow{2}{*}{$\mathrm{p}=0.234$} \\
\hline & No (16) & $4.29 / 39.95 / 55.12$ & \\
\hline \multirow{2}{*}{ Paracavernous growth } & Yes (18) & $1.95 / 44.29 / 76.80$ & \multirow{2}{*}{$\mathrm{p}=0.281$} \\
\hline & No (36) & $3.10 / 41.04 / 76.80$ & \\
\hline \multirow{2}{*}{ Parasphenoidal growth } & Yes (24) & $1.95 / 42.12 / 76.80$ & \multirow{2}{*}{$\mathrm{p}=0.700$} \\
\hline & No $(30)$ & $3.10 / 42.12 / 76.80$ & \\
\hline
\end{tabular}

*:Mann-Whitney U test; IL-17A: interleukin-17A. 
higher in patients with invasive PAs than in the group with noninvasive PAs. Serum level of IL-17A was found to be 95.46 $\pm 34.09 \mathrm{pg} / \mathrm{mL}$ in invasive PA patients, $56.26 \pm 14.03 \mathrm{pg} / \mathrm{mL}$ in noninvasive PA patients, and $23.58 \pm 6.55 \mathrm{pg} / \mathrm{mL}$ in the control group. In our study we revealed that serum level of IL-17A was significantly higher in patients with PA than in the control group (42.12 versus $8.19 \mathrm{pg} / \mathrm{mL}, \mathrm{p}<0.001)$. Unfortunately, the results of our study did not reveal any significant differences between IL-17A serum concentration and PA growth type. We can hypothesize that cytokine IL-17A can be important for PA development but it has no impact on PA growth type.

Overall, the present study demonstrated that impact of Ki-67 LI and IL-17A on PA invasiveness, recurrence, and tumour growth type requires further investigation with increased sample sizes to confirm the association of Ki-67 LI and IL-17A in patients with PA.

\section{Data Availability}

The data supporting the results reported in the article are not publicly available.

\section{Conflicts of Interest}

None of the authors has any proprietary interests or conflicts of interest related to this paper.

\section{Acknowledgments}

The present study received funding from the Research Council of Lithuania (grant no. MIP008/2014). The authors thank Dr. Silvija Jakstiene for radiological data evaluation.

\section{References}

[1] S. Ezzat, S. L. Asa, W. T. Couldwell et al., "The prevalence of pituitary adenomas: a systematic review," Cancer, vol. 101, no. 3, pp. 613-619, 2004.

[2] C. Destrieux, M. K. Kakou, S. Velut, T. Lefrancq, and M. Jan, "Microanatomy of the hypophyseal fossa boundaries," Journal of Neurosurgery, vol. 88, no. 4, pp. 743-752, 1998.

[3] A. Colao, C. di Somma, R. Pivonello, A. Faggiano, G. Lombardi, and S. Savastano, "Medical therapy for clinically nonfunctioning pituitary adenomas," Endocrine-Related Cancer, vol. 15, no. 4, pp. 905-915, 2008.

[4] R. Kasputytè, G. Slatkevičienè, R. Liutkevičienè, B. Glebauskienè, G. Bernotas, and A. Tamašauskas, "Changes of Visual Functions in Patients With Pituitary Adenoma," Medicina, vol. 49, no. 3, p. 21, 2013.

[5] E. Knosp, E. Steiner, K. Kitz, and C. Matula, "Pituitary adenomas with invasion of the cavernous sinus space: a magnetic resonance imaging classification compared with surgical findings," Neurosurgery, vol. 33, no. 4, pp. 610-618, 1993.

[6] E. Ferrante, M. Ferraroni, T. Castrignanò et al., "Non-functioning pituitary adenoma database: a useful resource to improve the clinical management of pituitary tumors," European Journal of Endocrinology, vol. 155, no. 6, pp. 823-829, 2006.
[7] J. Ahmadi, C. North, H. Segall, C. Zee, and M. Weiss, "Cavernous sinus invasion by pituitary adenomas," American Journal of Roentgenology, vol. 146, no. 2, pp. 257-262, 1986.

[8] R. Fahlbusch and M. Buchfelder, "Transsphenoidal surgery of parasellar pituitary adenomas," Acta Neurochirurgica, vol. 92, no. 1-4, pp. 93-99, 1988.

[9] B. W. Scheithauer, K. T. Kovacs, E. R. Laws Jr., and R. V. Randall, "Pathology of invasive pituitary tumors with special reference to functional classification," Journal of Neurosurgery, vol. 65, no. 6, pp. 733-744, 1986.

[10] C. Dai, M. Feng, X. Liu et al., "Refractory pituitary adenoma: A novel classification for pituitary tumors," Oncotarget, vol. 7, no. 50, pp. 83657-83668, 2016.

[11] C. H. Moon, S. C. Hwang, B.-T. Kim, Y.-H. Ohn, and T. K. Park, "Visual prognostic value of optical coherence tomography and photopic negative response in chiasmal compression," Investigative Ophthalmology \& Visual Science, vol. 52, no. 11, pp. 8527-8533, 2011.

[12] R. Thomas, K. Shenoy, M. S. Seshadri, J. Muliyil, A. Rao, and P. Paul, "Visual field defects in non-functioning pituitary adenomas," Indian Journal of Ophthalmology, vol. 50, pp. 127$130,2002$.

[13] J. C. Trautmann and E. R. Laws Jr., "Visual status after transphenoidal surgery at the Mayo Clinic 1971-1982," American Journal of Ophthalmology, vol. 96, pp. 200-208, 1983.

[14] A. Kaur, D. Banerji, D. Kumar, and K. Sharma, "Visual status in suprasellar pituitary tumours.," Indian Journal of Ophthalmology, vol. 43, no. 3, pp. 131-134, 1995.

[15] P. Mortini, M. Losa, R. Barzaghi, N. Boari, and M. Giovanelli, "Results of transsphenoidal surgery in a large series of patients with pituitary adenoma," Neurosurgery, vol. 56, no. 6, pp. 1222$1233,2005$.

[16] M. El-Azouzi, P. Mclaren Black, G. Candia, N. T. Zervas, and K. P. Pan s, "Transsphenoidal surgery for visual loss in patients with pituitary adenomas," Neurological Research, vol. 12, no. 1, pp. 23-25, 1990.

[17] M. Marazuela, B. Astigarraga, A. Vicente et al., "Recovery of visual and endocrine function following transsphenoidal surgery of large nonfunctioning pituitary adenomas," Journal of Endocrinological Investigation, vol. 17, no. 9, pp. 703-707, 1994.

[18] J. A. Gondim, J. P. C. Almeida, L. A. F. Albuquerque, M. Schops, É. Gomes, and T. Ferraz, "Headache associated with pituitary tumors," The Journal of Headache and Pain, vol. 10, no. 1, pp. 15-20, 2009.

[19] M. J. Levy, H. R. Jäger, M. Powell, M. S. Matharu, K. Meeran, and P. J. Goadsby, "Pituitary Volume and Headache: Size Is Not Everything," JAMA Neurology, vol. 61, no. 5, pp. 721-725, 2004.

[20] T. Endo, Y. Ogawa, M. Watanabe, and T. Tominaga, "A Case of Pituitary Carcinoma Initially Diagnosed as an Ectopic Growth Hormone Producing Pituitary Adenoma with a High Ki-67 Labeling Index," Journal of Neurological Surgery Part A: Central European Neurosurgery.

[21] A. Hadzhiyanev, R. Ivanova, E. Nachev et al., "Evaluation of prognostic utility of MIB-1 and p53 expression in pituitary adenomas: Correlations with clinical behaviour and follow-up results," Biotechnology \& Biotechnological Equipment, vol. 28, no. 3, pp. 502-507, 2014.

[22] F. S. Harris and A. L. Rhoton Jr., "Anatomy of the cavernous sinus. A microsurgical study," Journal of Neurosurgery, vol. 45, no. 2, pp. 169-180, 1976. 
[23] C. B. Wilson, "Neurosurgical management of large and invasive pituitary tumors," in Clinical management of pituitary disorders, G. T. Tindall, Ed., pp. 335-342, Raven, New York, NY, USA, 1979.

[24] J. Wang, B. Voellger, J. Benzel et al., "Metalloproteinases ADAM12 and MMP-14 are associated with cavernous sinus invasion in pituitary adenomas," International Journal of Cancer, vol. 139, no. 6, pp. 1327-1339, 2016.

[25] B. Sun, X. Liu, Y. Yang et al., "The Clinical Utility of TIMP3 Expression in ACTH-Secreting Pituitary Tumor," Journal of Molecular Neuroscience, vol. 58, no. 1, pp. 137-144, 2016.

[26] I. Wierzbicka-Tutka, G. Sokołowski, A. Bałdys-Waligórska, D. Adamek, E. Radwańska, and F. Gołkowski, "PTTG and Ki-67 expression in pituitary adenomas," Przegląd Lekarski, vol. 73, no. 2, pp. 53-58, 2016.

[27] L. Mastronardi, A. Guiducci, and F. Puzzilli, "Lack of correlation between Ki-67 labelling index and tumor size of anterior pituitary adenomas., BMC cancer [electronic resource], vol. 1, no. 1, p. 12, 2001.

[28] K. Thapar, K. Kovacs, B. W. Scheithauer et al., "Proliferative activity and invasiveness among pituitary adenomas and carcinomas: an analysis using the MIB-1 antibody," Neurosurgery, vol. 38, no. 1, pp. 99-107, 1996.

[29] K. Kitz, E. Knosp, W. T. Koos, and A. Korn, "Proliferation in Pituitary Adenomas: Measurement by MAb KI 67," in Processes of the Cranial Midline, vol. 53 of Acta Neurochirurgica Supplementum, pp. 60-64, Springer Vienna, Vienna, 1991.

[30] A. Sadeghipour, L. Mahouzi, M. M. Salem et al., "Ki67 labeling correlated with invasion but not with recurrence," Applied Immunohistochemistry \& Molecular Morphology, vol. 25, no. 5, pp. 341-345, 2017.

[31] H. A. Zaidi, D. J. Cote, I. F. Dunn, and E. R. Laws, “Predictors of aggressive clinical phenotype among immunohistochemically confirmed atypical adenomas," Journal of Clinical Neuroscience, vol. 34, pp. 246-251, 2016.

[32] J. A. Landeiro, E. O. Fonseca, A. L. Cruz Monnerat, G. F. Taboada, G. A. P. Sereno Cabral, and F. Antunes, "Nonfunctioning giant pituitary adenomas: Invasiveness and recurrence," Surgical Neurology International, vol. 6, no. 1, article no. 179, 2015.

[33] S. Yarman, N. Kurtulmus, A. Canbolat, C. Bayindir, B. Bilgic, and N. Ince, "Expression of Ki-67, p53 and vascular endothelial growth factor (VEGF) concomitantly in growth hormonesecreting pituitary adenomas; which one has a role in tumor behavior?" Neuroendocrinology Letters, vol. 31, no. 6, pp. 823$828,2010$.

[34] S. Dubois, S. Guyétant, P. Menei et al., "Relevance of Ki-67 and prognostic factors for recurrence/progression of gonadotropic adenomas after first surgery," European Journal of Endocrinology, vol. 157, no. 2, pp. 141-147, 2007.

[35] R. Gandour-Edwards, S. B. Kapadia, I. P. Janecka, A. J. Martinez, and L. Barnes, "Biologic markers of invasive pituitary adenomas involving the sphenoid sinus," Modern Pathology, vol. 8, no. 2, pp. 160-164, 1995.

[36] E. Tartour, F. Fossiez, I. Joyeux et al., "Interleukin 17, a T-cellderived cytokine, promotes tumorigenicity of human cervical tumors in nude mice," Cancer Research, vol. 59, no. 15, pp. 36983704, 1999.

[37] L. Wang, T. Yi, M. Kortylewski, D. M. Pardoll, D. Zeng, and H. Yu, "IL-17 can promote tumor growth through an IL-6-Stat3 signaling pathway," The Journal of Experimental Medicine, vol. 206, no. 7, pp. 1457-1464, 2009.
[38] J. P. Zhang, J. Yan, J. Xu et al., "Increased intratumoral IL-17producing cells correlate with poor survival in hepatocellular carcinoma patients," Journal of Hepatology, vol. 50, no. 5, pp. 980-989, 2009.

[39] J.-S. Nam, M. Terabe, M.-J. Kang et al., “Transforming growth factor beta subverts the immune system into directly promoting tumor growth through interleukin-17,' Cancer Research, vol. 68, no. 10, pp. 3915-3923, 2008.

[40] F. Benchetrit, A. Ciree, V. Vives et al., "Interleukin-17 inhibits tumor cell growth by means of a T-cell-dependent mechanism," Blood, vol. 99, no. 6, pp. 2114-2121, 2002.

[41] N. Hirahara, Y. Nio, S. Sasaki et al., "Inoculation of human interleukin-17 gene-transfected Meth-A fibrosarcoma cells induces T cell-dependent tumor-specific immunity in mice," Oncology, vol. 61, no. 1, pp. 79-89, 2001.

[42] L. Qiu, D. He, X. Fan et al., "The expression of interleukin (IL)-17 and IL-17 receptor and MMP-9 in human pituitary adenomas," The Pituitary Society, vol. 14, no. 3, pp. 266-275, 2011.

[43] L. Qiu, J. Yang, H. Wang, Y. Zhu, Y. Wang, and Q. Wu, "Expression of T-helper-associated cytokines in the serum of pituitary adenoma patients preoperatively and postperatively," Medical Hypotheses, vol. 80, no. 6, pp. 781-786, 2013.

[44] M. Al-Shraim and S. L. Asa, "The 2004 World Health Organization classification of pituitary tumors: what is new?" Acta Neuropathologica, vol. 111, no. 1, pp. 1-7, 2006.

[45] K.-I. Paek, S.-H. Kim, S.-H. Song et al., "Clinical significance of Ki-67 labeling index in pituitary macroadenoma," Journal of Korean Medical Science, vol. 20, no. 3, pp. 489-494, 2005. 


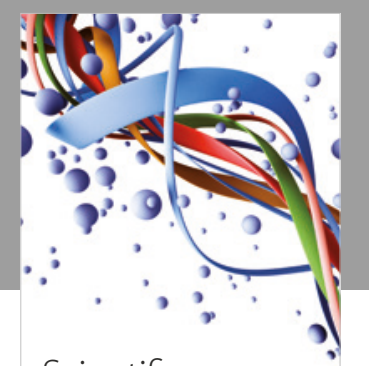

Scientifica
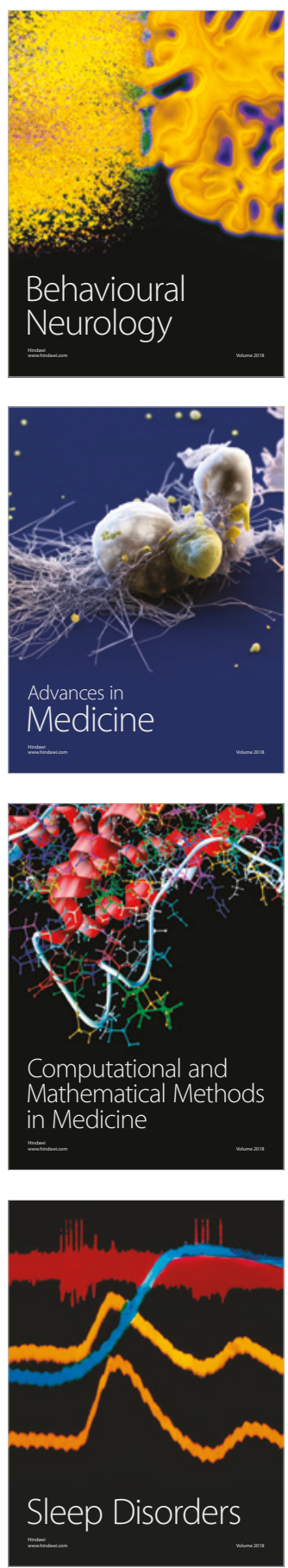

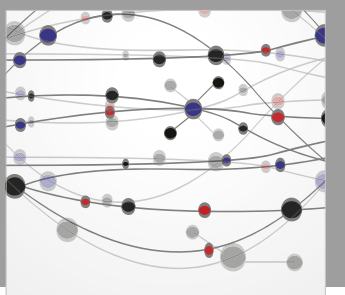

The Scientific World Journal

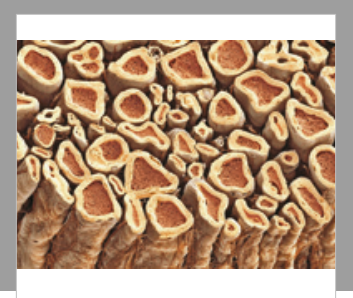

Case Reports in

Neurological Medicine

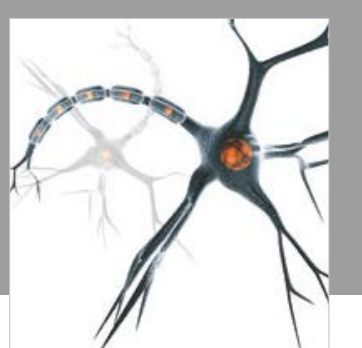

Neural Plasticity

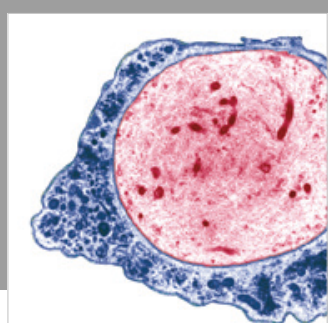

Multiple Sclerosis

International

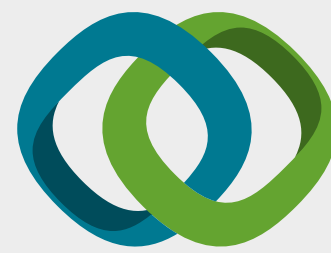

Hindawi

Submit your manuscripts at

www.hindawi.com
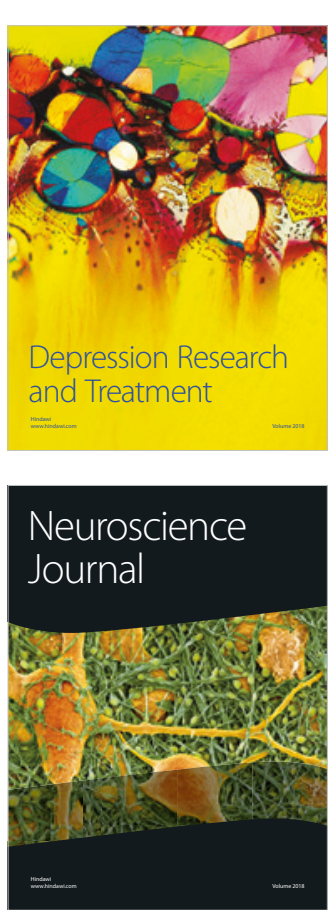

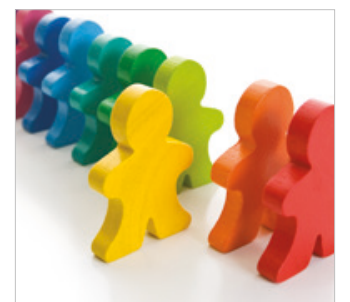

Autism

Research and Treatment
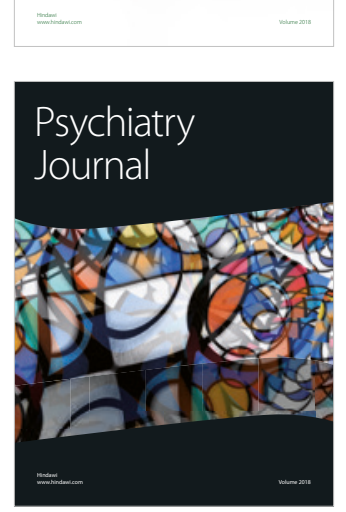
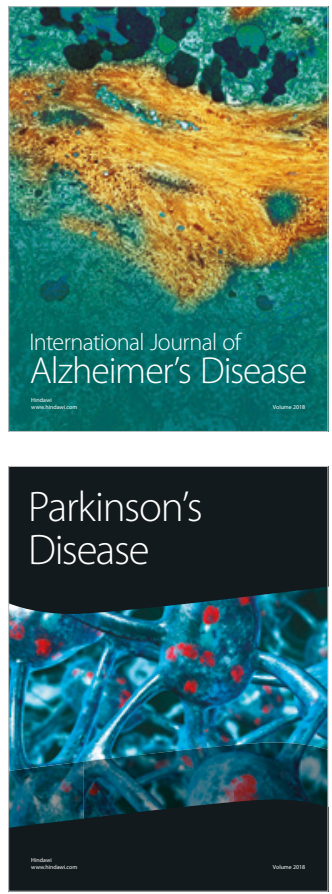
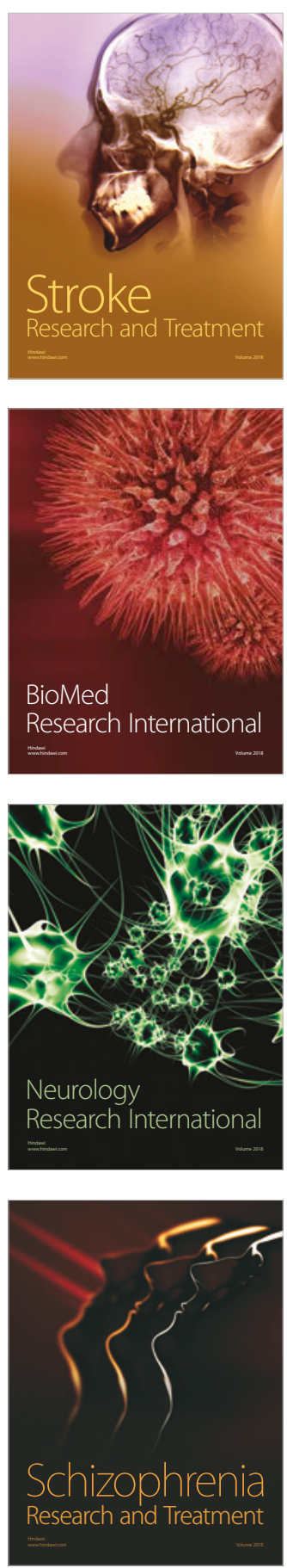